\title{
SENSITIVITY TO IVERMECTIN AND PYRANTEL OF ANCYLOSTOMA CEYLANICUM AND NECATOR AMERICANUS
}

\author{
JeRzy M. BehnKE*, Richard Rose and PaUl GaRside $\dagger$ \\ MRC Experimental Parasitology Group, Department of Life Science, University of Nottingham, University Park, \\ Nottingham NG7 2RD, U.K.
}

(Received 4 November 1992; accepted 10 April 1993)

\begin{abstract}
Behnke J.M., Rose R. and Garside P. 1993. Sensitivity to ivermectin and pyrantel of Ancylostoma ceylanicum and Necator americanus. International Journal for Parasitology 23: 945-952. Experiments were carried out in the hamster to compare the relative susceptibility of Necator americanus and Ancylostoma ceylanicum to treatment with ivermectin. A.ceylanicum was found to be 300 times more sensitive to the anthelmintic with a $50 \%$ effective dose $\left(\mathrm{ED}_{50}\right)$ of the order of $10-15 \mu \mathrm{g} \mathrm{kg}^{-1}$ body weight whilst that for N.americanus approximated to $3-5 \mathrm{mg} \mathrm{kg}^{-1}$. Furthermore, whereas complete clearance of A.ceylanicum was observed with a dose of $100 \mu \mathrm{g} \mathrm{kg}^{-1}$, N.americanus was not totally removed after treatment with $25 \mathrm{mg} \mathrm{kg}$ ', the highest dose tested. Both parasites proved equally sensitive to pyrantel with an $\mathrm{ED}_{50}$ of $1-12 \mathrm{mg} \mathrm{kg}^{-1}$ for A.ceylanicum and $5-25 \mathrm{mg} \mathrm{kg}^{-1}$ for $N$.americanus. Treatment with pyrantel at $100 \mathrm{mg} \mathrm{kg}^{-1}$ completely eliminated worms of both species and doses of $25-50 \mathrm{mg} \mathrm{kg}^{-1}$ were $>90 \%$ effective. In addition to worm burdens, changes in host weight and PCV were also recorded and it was shown that both parameters could be used to evaluate the success/failure of treatment.
\end{abstract}

INDEX KEY WORDS: Necator americanus; Ancylostoma ceylanicum; hamster; ivermectin; pyrantel.

\section{INTRODUCTION}

THE introduction of ivermectin, in 1981 as an antiparasitic drug for helminths and arthropods has had a marked impact on the treatment of animal diseases and recently, following successful trials in humans, a licence has been granted for treatment of patients with onchocerciasis (Campbell, 1985; Green, Brown \& Taylor, 1989). Many of the common gastrointestinal nematodes are highly susceptible to ivermectin, at concentrations measured in $\mu \mathrm{g} \mathrm{kg}^{-1}$ body weight, considerably smaller than the $\mathrm{mg} \mathrm{kg}^{-1}$ concentrations required for effective antiparasite activity of other anthelmintics. However, some parasites have proved to be exceptionally resistant to ivermectin, (Heligmosomoides polygyrus, Trichuris trichiura and hookworms; Wahid, Behnke \& Conway, 1989; Whitworth, Morgan, Maude, McNicholas \& Taylor, 1991).

Several field studies have shown that ivermectin, at the doses suitable for treatment of humans, has little

*To whom all correspondence should be addressed.

†Present address; Department of Immunology, Western Infirmary, University of Glasgow, Glasgow G11 6NT, U.K. impact on hookworm infection (Whitworth et al., 1991; Richard-Lenoble, Kombila, Rupp, Pappayliou, Gaxotte, Nguiri \& Aziz, 1988). However, these observations contrast with the results of studies in animals which have indicated that Ancylostoma spp. are susceptible (Egerton, Eary \& Suhayda, 1985). Field data is mostly based on Necator americanus, a human hookworm which has no close relative among laboratory-maintained animal parasites and which itself cannot be easily maintained in dogs, the hosts generally used for chemotherapeutic studies of hookworm infection (Behnke, 1990). The implied difference in relative susceptibility to ivermectin of hookworm species from the genera Ancylostoma and Necator therefore requires urgent evaluation. In this paper we describe experiments in which we compared the relative susceptibility to ivermectin of Ancylostoma ceylanicum and N.americanus in hamsters, a host in which both species develop to patent infection. Our results establish that there is indeed a profound difference in susceptibility to ivermectin.

\section{MATERIALS AND METHODS}

Parasites and hosts. Infective larvae of N.americanus were obtained in 1983 from Dr Rajasekariah of CIBA-GEIGY 
TABLE 1.--EXPERIMENTAL DESIGN

\begin{tabular}{rclclcc}
\hline Experiment & $\begin{array}{c}\text { No. of } \\
\text { hamsters/ } \\
\text { group }\end{array}$ & Parasite* & $\begin{array}{c}\text { No. of larvae } \\
\text { administered }\end{array}$ & $\begin{array}{c}\text { Anthelmintic } \dagger \\
\text { Interval to } \\
\text { autopsy } \\
\text { (days) }\end{array}$ \\
\hline 1 & 3 & A.ceylanicum & 50 & Ivermectin & $\begin{array}{c}\text { Day of } \\
\text { infection } \\
\text { when treated }\end{array}$ & 18 \\
2 & 3 & A.ceylanicum & 100 & Ivermectin & 21 & 3 \\
3 & $4-5$ & A.ceylanicum & 70 & Ivermectin & 22 & 3 \\
4 & 3 & N.americanus & 108 & Ivermectin & 35 & 3 \\
5 & 3 & N.americanus & 144 & Ivermectin & 35 & 3 \\
6 & $4-5$ & N.americanus & 100 & Ivermectin & 28 & 8 \\
7 & 3 & A.ceylanicum & 100 & Pyrantel & 21 & 3 \\
8 & $4-6$ & A.ceylanicum & 50 & Pyrantel & 21 & 7 \\
9 & $4-5$ & A.ceylanicum & 66 & Pyrantel & 22 & 6 \\
10 & 3 & N.americanus & 108 & Pyrantel & 35 & 3 \\
11 & 3 & N.americanus & 160 & Pyrantel & 35 & 3 \\
12 & 3 & N.americanus & 70 & Pyrantel & 30 & 7 \\
\hline
\end{tabular}

*Ancylostoma ceylanicum larvae were administered orally to mature hamsters. Necator americanus larvae were given percutaneously to neonatal (2-3-day-old) hamsters.

†Ivermectin was administered subcutaneously. Pyrantel was given orally.

Hindustan Ltd., Bombay, India and the parasite has been maintained since by regular passage through hamsters as described originally by Sen (1972) and Behnke, Wells \& Brown (1986). It is important to note here that N.americanus will only mature to patency following exposure of neonatal (1-3-day-old) hamsters to infection (Rajasekariah, Deb, Dhage \& Bose, 1985). Experiments with N.americanus were therefore limited by the need for synchronized mating of female hamsters and by resulting litter sizes. A.ceylanicum was also obtained from Dr Rajasekariah and was passaged through adult hamsters using techniques which have been described by Garside \& Behnke (1989). All the animals used in this work were syngeneic DSN hamsters originally purchased from Intersimian Ltd, Oxford, U.K., but now maintained, under conventional conditions with access to food and water ad libitum, as a closed breeding colony in the Department of Life Science at Nottingham University. Both sexes were used but all the animals in any one experiment were of the same sex. Experimental groups were set up in separate cages at least 1-2 weeks before infection. In some experiments all individuals were weighed a week before infection, on the day of infection and treatment and on the day of autopsy. Fifty $\mu$ l blood samples were obtained in heparinized capillary tubes, under trilene anaesthesia for measurement of the packed cell volume (PCV) at times stated.

Anthelmintic treatment. Ivermectin was available as a commercial preparation, Ivomec which contains $1 \% \mathrm{w} / \mathrm{v}$ of the anthelmintic (Merck Sharp \& Dohme AGVET). The required concentrations of ivermectin were obtained by appropriate dilution of this preparation with sterile distilled water. The resulting fine suspension was injected subcutaneously in volumes of $0.05-0.4 \mathrm{ml}$ within minutes of preparation. Pyrantel embonate (Strongid-P paste, Pfizer) was administered orally to hamsters after appropriate dilution of the stock with sterile distilled water.

Statistical analysis of results. The results are presented as group mean values (MWR) \pm standard error (S.E.M.). Non- parametric statistical procedures were used to analyse the data sets, because small sample sizes precluded the assumption of normal distribution (Sokal \& Rohlf, 1969). When more than 2 groups required comparison at a single time point the Kruskal-Wallis statistic $H$ was calculated to determine whether there was a significant treatment effect. If significant, specific groups were compared to the control group (or as stated) by the Mann-Whitney $U$-test. Correlations between variables were tested by the Spearman Rank Order Correlation Test and the statistic $r_{5}$ is given, as appropriate. Probabilities were calculated from statistics tables and are presented as follows: ${ }^{*} P=0.05 ; * * 0.05>P$ $\geq 0.02$; **0.02 $>P \geq 0.01$; ***0.01 $>P \geq 0.001$; ***** $P<0.001$.

\section{RESULTS}

\section{Effect of ivermectin on A.ceylanicum}

In a preliminary experiment (Experiment 1) 5 groups of hamsters, each of 3 animals, were treated either with $20,5,1.25$ or $0.31 \mathrm{mg} \mathrm{kg} \mathrm{k}^{-1}$ body weight of ivermectin subcutaneously 18 days after exposure to $50 \mathrm{~L} 3$. One group was left untreated. When killed 3 days after treatment worms were recovered only from the control untreated animals $(20.3 \pm 4.6)$.

Two further experiments were then carried out to establish the cut-off point for drug efficacy and to obtain data for $50 \%$ effective dose $\left(\mathrm{ED}_{50}\right)$ and complete clearance of worms. The experimental design of this (and all other experiments) is given in Table 1 and the results are illustrated in Fig. 1(A). A. ceylanicum proved to be sensitive to ivermectin with a significant reduction in worm burden being achieved with doses of $10-100 \mu \mathrm{g} \mathrm{kg}^{-1}$ body weight. However, complete clearance of worms required $100-500 \mu \mathrm{g} \mathrm{kg}^{-1}$ body weight. 


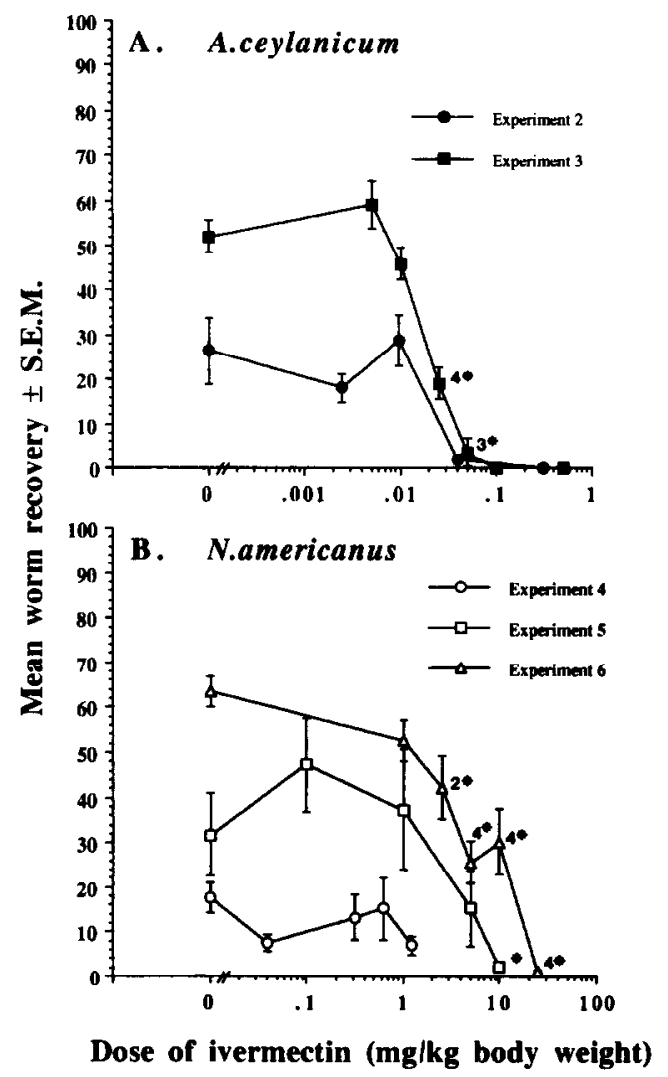

FIG. 1. Ancylostoma ceylanicum and Necator americanus adult worm burdens in hamsters treated with various doses of ivermectin. For details of the experimental designs see Table 1. Statistical analysis: Groups were compared to the untreated control group in each case. ${ }^{*} P=0.05 ; 2 * 0.05>$

$P \geq 0.025 ; 3^{*} 0.025>P \geq 0.01 ; 4^{*} 0.01>P \geq 0.001$.

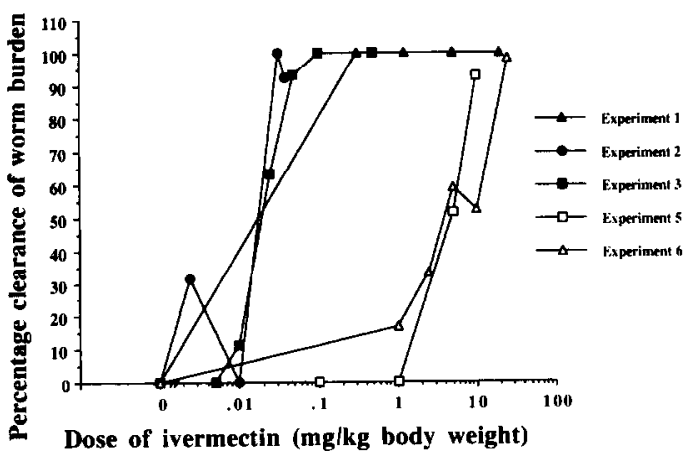

FIG. 2. Comparison of the efficacy of ivermectin against Ancylostoma ceylanicum and Necator americanus. Solid symbols represent experiments with A.ceylanicum and open symbols $N$.americanus.

\section{Effect of ivermectin on $\mathrm{N}$.americanus}

Three experiments were carried out to determine the efficacy of ivermectin against $N$.americanus (Experi- ments 4-6). The doses investigated are given in Fig. 1(B). In Experiment 4 no significant reduction in worm burden was obtained when doses ranging from $39 \mu \mathrm{g}$ to $1.25 \mathrm{mg} \mathrm{kg}^{-1}$ were examined. In Experiment $5,5 \mathrm{mg}$ $\mathrm{kg}^{-1}$ resulted in a $51.6 \%$ reduction in worm burden but because of small group size and variation in worm establishment this was not a significant reduction. However, $10 \mathrm{mg} \mathrm{kg}^{-1}$, gave $92.6 \%$ clearance of worms $(P=0.05)$. In Experiment 6, a dose of $5 \mathrm{mg} \mathrm{kg}^{-1}$ gave $59.4 \%$ protection $(P=0.008)$ and a significant effect was also detected with $2.5 \mathrm{mg} \mathrm{kg}^{-1}$ (33.4\% reduction, $P<0.032)$ but complete clearance of worms was not achieved even with a dose of $25 \mathrm{mg} \mathrm{kg}^{-1}(98.4 \%$ reduction in worm burden). The results therefore show that $N$.americanus is not affected by doses lower than $2.5 \mathrm{mg} \mathrm{kg}^{-1}$ and that complete clearance of worms requires doses in excess of $25 \mathrm{mg} \mathrm{kg}^{-1}$.

Comparison of the effect of ivermectin on A. ceylanicum and $\mathrm{N}$.americanus

Figure 2 summarizes the data from 5 experiments. Experiment 4 was omitted because none of the doses examined were effective against $N$.americanus. It can be seen that $\mathrm{ED}_{50}$ for A.ceylanicum is of the order of $10-15 \mu \mathrm{g} \mathrm{kg}^{-1}$ whilst that of N.americanus approximates to $3-5 \mathrm{mg} \mathrm{kg}^{-1}$. On the basis of these results A.ceylanicum is approximately 300 times more sensitive to ivermectin than N.americanus. Likewise, whereas complete clearance of A.ceylanicum was observed with a dose of $100 \mu \mathrm{g} \mathrm{kg}^{-1}, N$.americanus was not totally removed after treatment with $25 \mathrm{mg} \mathrm{kg}^{-1}$, the highest dose tested.

Comparison of the effect of pyrantel on A.ceylanicum and N.americanus

The difference in sensitivity to ivermectin between these 2 hookworm species prompted us to compare sensitivity to pyrantel, an anthelmintic known to have comparable efficacy against worms of both genera. We were particularly concerned that our results with ivermectin might reflect an artifact of the system rather than an intrinsic difference in drug sensitivity. Therefore, 6 further experiments were carried out in which hamsters were infected with either A.ceylanicum or $N$.americanus and were treated with various doses of pyrantel.

The results of 5 experiments are summarized in Figs. 3 and 4. Experiment 10, which is not illustrated, comprised 5 groups of 3 hamsters each exposed to 164 L3 of N.americanus. Four of the groups were dosed 35 days p.i. with either $1,2.5,5.0$ or $10 \mathrm{mg} \mathrm{kg}^{-1}$ of pyrantel. The recovery of worms from the control group on this occasion was more variable than normal $(49.3 \pm 25.4)$ and there was no evidence of an effect at $5 \mathrm{mg} \mathrm{kg}^{-1}(57.0 \pm 23.52)$ but the group treated with 10 


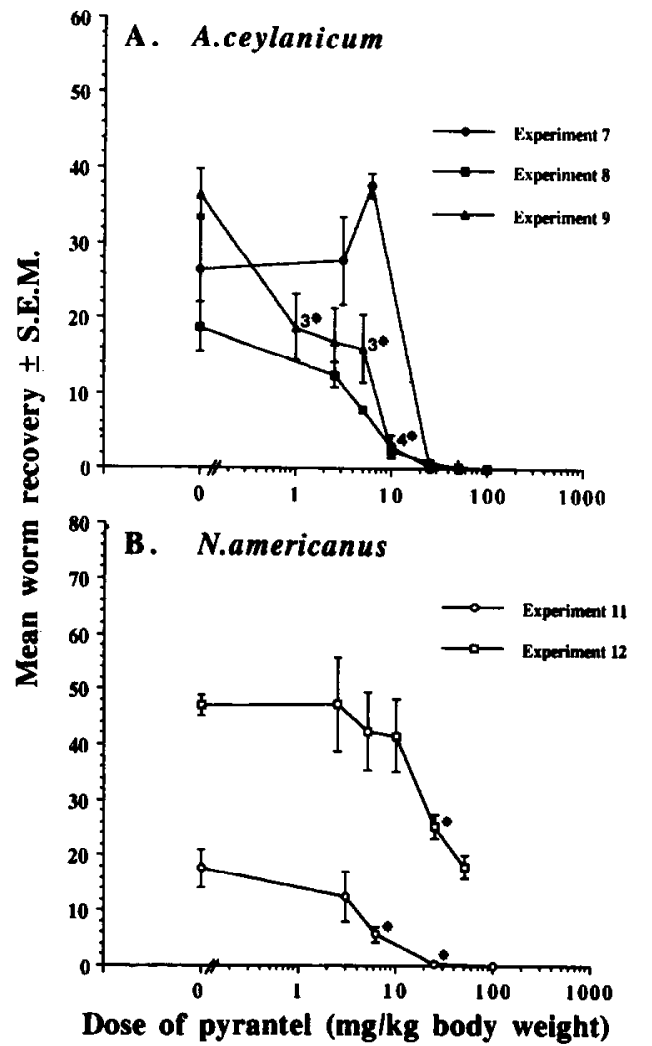

Fig. 3. Ancylostoma ceylanicum and Necator americanus adult worm burdens in hamsters treated with various doses of pyrantel. For details of the experimental designs see Table 1. Statistical analysis: Groups were compared to the untreated control group in each case. * $P=0.05 ; 3^{*} 0.025>P \geq 0.01$; 4*0.01>P $\geq 0.001$.

$\mathrm{mg} \mathrm{kg} \mathrm{kg}^{-1}$ had a $50 \%$ reduction relative to the control group $(24.67 \pm 11.3)$. This result was broadly confirmed in Experiment 11 in which $6.1 \mathrm{mg} \mathrm{kg}^{-1}$ gave $67.9 \%$ protection (Fig. 3B). However, in Experiment 12 N.americanus appeared to be less sensitive with 10 $\mathrm{mg} \mathrm{kg}^{-1}$ giving only a $11.3 \%$ reduction relative to controls and $25 \mathrm{mg} \mathrm{kg}^{-1} 46.1 \%$ (Fig. 3B). The animals in Experiment 12 harboured heavier worm burdens than those in Experiment 11 and this may have been a factor affecting overall drug efficacy.

The sensitivity of A.ceylanicum to pyrantel was similar to that of N.americanus (Fig. 3A). Again, there was some variation between the experiments but $L_{50}$ approximated to $1-12 \mathrm{mg} \mathrm{kg}^{-1}$ for A.ceylanicum and 5-25 $\mathrm{mg} \mathrm{kg}^{-1}$ for N.americanus (Fig. 4). The lowest dose of pyrantel giving complete elimination of $A$. ceylanicum was $25 \mathrm{mg} \mathrm{kg}^{-1}$ in Experiment 7, but the same dose left a few worms in Experiments 8 and 9 ( 98.9 and $97.8 \%$ protection, respectively). Fifty $\mathrm{mg}$ $\mathrm{kg}^{-1}$ completely cleared worms in Experiment 9 but

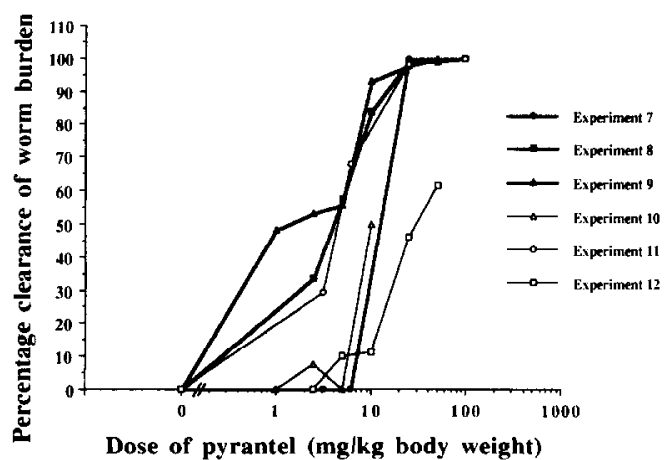

Fig. 4. Comparison of the efficacy of pyrantel against Ancylostoma ceylanicum and Necator americanus. Solid symbols represent experiments with A.ceylanicum and open symbols $N$.americanus.

left some adult worms in Experiment 8 (98.9\% protection). Therefore, the minimum dose which guaranteed complete removal of all adult worms was established as $100 \mathrm{mg} \mathrm{kg}^{-1}$. This pattern was similar for N.americanus with $25 \mathrm{mg} \mathrm{kg}^{-1}$ giving $98.3 \%$ protection in Experiment 11 but only $46.1 \%$ in Experiment 12 . We tested $100 \mathrm{mg} \mathrm{kg}^{-1}$ on one occasion against $N$.americanus and the result was $100 \%$ clearance of all worms (Fig. 3B, Experiment 11).

Comparison of the effect of both anthelmintics on changes in weight and PCV of hamsters infected with A.ceylanicum and N.americanus

In addition to recording changes in worm burden following treatment we also monitored changes in PCV (Fig. 5) and body weight (not illustrated) in some experiments. Normal PCV values in adult hamsters average about $52 \%$ with a range from 50 to $55 \%$ (Fig. 5C). In Experiments 3 and 9, in which adult hamsters were infected with A.ceylanicum, PCV dropped uniformly to just below $30 \%$ (Experiment 3 ) or just above $30 \%$ (Experiment 9 ) in all groups by 7 or 6 days p.i., respectively. The difference in magnitude of the reduction of the PCVs was a reflection of the heavier mean worm burden in Experiment 3 (Fig. 1A, MWR $=52 \pm 7.1$ ) relative to that of Experiment 9 (Fig. 3A, MWR $=36.4 \pm 3.3$ ). Following treatment with either ivermectin or pyrantel at doses which did not reduce the worm burden, PCV remained depressed. However, all groups in which trcatment resulted in worm loss, had improved PCV with restoration closest to normal levels in those groups which showed more than $90 \%$ reduction in worm burdens. Worm loss was closely paralleled by increase in PCV (Experiment 3, $r_{\mathrm{s}}=$ $0.82, P=0.024$; Experiment $9, r_{\mathrm{s}}=0.922, P=0.001$ ) over the period between treatment and autopsy for worm counts. 


\section{A.ceylanicum}

A. Experiment 3, Ivermectin

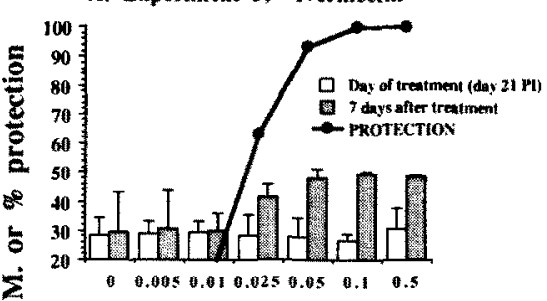

C. Experiment 9, Pyrantel

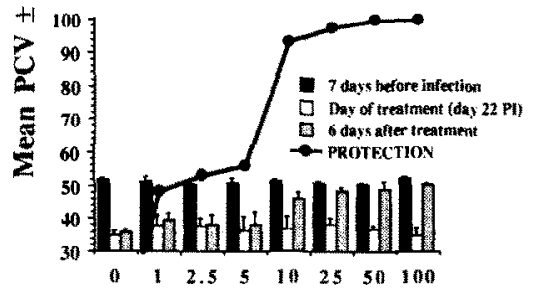

Namericanus

B. Experiment 6, Ivermectin

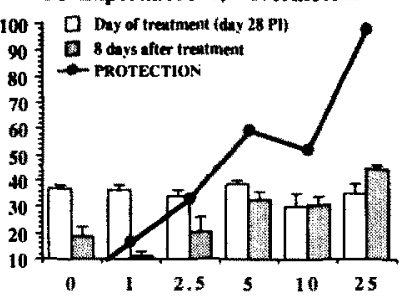

D. Experiment 12, Pyrantel

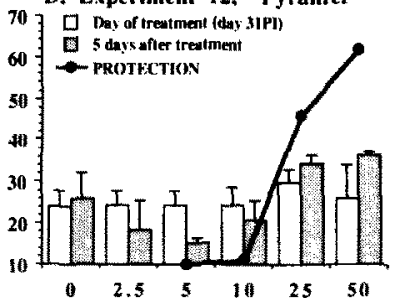

(mg/kg body weight)

Fic. 5. Relationship between changes in $\mathrm{PCV}$ in the period between treatment and autopsy, and protection ( $\%$ of worm burden lost) as a result of treatment.

The data for changes in weight were less clear-cut, but nevertheless support similar conclusions to those linking worm counts and changes in PCV. In Experiment 3 the mean weight of the untreated control group was less on the day of autopsy than on the day of treatment $(97.4 \pm 23.7,104.4 \pm 16.4$, respectively) and similar losses of weight were detected in animals given 5 or $10 \mu \mathrm{g} \mathrm{kg}^{-1}$ of ivermectin in which there was no loss of worms following treatment. All the groups treated with ivermectin at more than $25 \mu \mathrm{g} \mathrm{kg}^{-1} \mathrm{had}$ higher means, indicating that there was some weight gain (e.g. hamsters given $100 \mu \mathrm{g} \mathrm{kg}^{-1}$ weighed $104.5 \pm$ $6.4 \mathrm{~g}$ on the day of treatment and $110.2 \pm 5.1 \mathrm{~g}, 7$ days later at autopsy), but there were no significant differences between the groups. In Experiment 9, where the number of worms establishing was lower than in Experiment 3, all groups (except animals treated with $5 \mathrm{mg} \mathrm{kg}^{-1}$ which lost $2 \mathrm{gm}$ ) continued to increase in weight between the day of treatment with pyrantel and autopsy. The mean weight gain in groups given pyrantel at $10 \mathrm{mg} \mathrm{kg}^{-1}$ or more ranged from 6.1 to 11.2 g. In contrast those groups receiving less than $10 \mathrm{mg}$ $\mathrm{kg}^{-1}$ showed a maximum mean weight gain of $4.25 \mathrm{~g}$. Thus, there was some indication that animals in which the worm burden was effectively reduced gained weight faster than those in which the parasites persisted.

In experiments with N.americanus the interval between infection and autopsy was longer because N.americanus moult to the preadult stage 21-23 days p.i. and do not become patent until after 4 weeks of infection. The effect of N.americanus on the PCV was more severe in Experiments 6 and 12 than that of A.ceylanicum in Experiments 3 and 9 and, as can be seen from Figs. 5(B) and (D), PCVs continued to decline in animals which were not treated and in those given doses of anthelmintic which failed to make a significant impact on the worm burdens. In Experiment 6 hamsters given more than $5 \mathrm{mg} \mathrm{kg}^{-1}$ of ivermectin (Fig. 5B) either stabilized their PCV or showed an increase over the interval between treatment and autopsy. There was a significant relationship between the change in PCV and loss of worms following treatment with anthelmintic $\left(r_{s}=0.886, P\right.$ $=0.019$ ). However, in Experiment 12 where a shorter interval separated treatment and assessment of PCV (5 days) this relationship was not significant $\left(r_{\mathrm{s}}=0.667\right)$.

Changes in weight in Experiments 6 and 12 closely paralleled anthelmintic efficacy. Thus in Experiment 6 hamsters given $2.5 \mathrm{mg} \mathrm{kg}^{-1}$ of ivermectin or less, lost weight between treatment and autopsy, while those given more gained weight. There was an exception in the group given $10 \mathrm{mg} \mathrm{kg}^{-1}$, but this group also showed a smaller reduction in worms than animals given only $5 \mathrm{mg} \mathrm{kg}^{-1}$. Overall there was a perfect correlation between the change in weight and loss of worms following treatment $\left(r_{\mathrm{s}}=1, P<0.001\right)$. In Experiment 12, only hamsters given $2.5 \mathrm{mg} \mathrm{kg}^{-1}$ of pyrantel or untreated lost weight between treatment and autopsy (e.g. the mean weight of untreated controls was $42.8 \pm 2.7 \mathrm{~g}$ on the day of treatment and $42.4 \pm 6.8 \mathrm{~g}$ at autopsy). All groups given $5 \mathrm{mg} \mathrm{kg}^{-1}$, or more, gained weight (e.g. mean weight of hamsters given $50 \mathrm{mg} \mathrm{kg}^{-1}$ was $45.3 \pm 13.8$ and $57.4 \pm 16.9$ at 
treatment and autopsy, respectively). Again there was a significant relationship between the mean change in weight over the period from treatment to autopsy and loss of worms $\left(r_{\mathrm{s}}=0.928, P=0.008\right)$.

\section{DISCUSSION}

The results reported in this paper provide the first direct comparison of hookworm species from the two important genera Ancylostoma and Necator for their sensitivity to ivermectin. Ancylostoma is 300 times more sensitive than Necator to treatment with this anthelmintic. The relative insensitivity of $N$.americanus to ivermectin in the hamster model has been reported previously by Rajasekariah, Deb, Dhage \& Bose (1989) with a $\mathrm{ED}_{50}$ of $8.32 \mathrm{mg} \mathrm{kg}^{-1}$ (marginally higher than our estimate of $3-5 \mathrm{mg} \mathrm{kg}^{-1}$ ) and the minimum dose required for complete clearancc of worms calculated as $18 \mathrm{mg} \mathrm{kg}^{-1}$ (whereas we were unable to demonstrate total loss of worms with doses less than $25 \mathrm{mg} \mathrm{kg}^{-1}$ ).

This marked difference in sensitivity to ivermectin between hookworm genera has potential significance for the epidemiology of human hookworm infections in regions where A.duodenale and $N$.americanus are sympatric and where ivermectin is being used for the control of filariasis. Indeed there is already evidence from such studies in Africa that hookworm infections, which are predominantly $N$.americanus, are unaffected by ivermectin at the doses which are employed to treat communities with onchocerciasis (150 $\mu \mathrm{g} \mathrm{kg}^{-1}$, Whitworth et al., 1991) or loiasis $\left(5-200 \mu \mathrm{g} \mathrm{kg}^{-1}\right.$, Richard-Lenoble et al., 1988).

To our knowledge there is no clear-cut data on the effectiveness of ivermectin in patients with $A$.duodenale but in a study of patients harbouring single or mixed species infections Naquira, Jimenez, Guerra, Bernal, Nalin, Neu \& Aziz (1989) reported that doses ranging from 50 to $2 \times 200 \mu \mathrm{g} \mathrm{kg}^{-1}$ did not significantly affect prevalence of either species. At the highest dose level tested the cure rate was higher in patients harbouring A.duodenale alone compared with those harbouring N.americanus (67 and $38 \%$, respectively), perhaps indicating differential sensitivity but the sample sizes were too small to establish this point. However, there is considerable evidence from studies in animals that A.caninum in dogs (Egerton et al., 1985) and A.tubaeformae in cats (Fukase, In, Chinone, Akihama \& Itagaki, 1991) are readily affected by doses of ivermectin comparable to those which we employed. Wang, Huang, Zhang, Yen \& Wen (1989) reported complete clearance of A.caninum from dogs after treatment with only $10 \mu \mathrm{g} \mathrm{kg}^{-1}$ body weight, a dose corresponding in our study to $\mathrm{ED}_{s_{0}}$ for A.ceylanicum. In hamsters complete clearance of A.ceylanicum necessitated a minimum dose of $100 \mu \mathrm{g} \mathrm{kg}^{-1}$.
However, it is well established that the metabolic activity of small animals is higher than that of larger animals and there is a negative correlation between body size and $\mathrm{ED}_{50}$ as well as $\mathrm{ED}_{100^{\circ}}$. Thus, the 10-fold difference in the results reported here and those of Wang et al. (1989) is consistent with this interpretation, but we can only speculate until comparative experiments employing both Ancylostoma species in dogs are completed. The canine system could also be used to examine A.duodenale which can be maintained in dogs (Leiby, El Naggar \& Schad, 1987).

We were concerned that the difference between species in sensitivity to ivermectin may be attributable to some artifactual consequence of the experimental system which we employed (see Behnke, 1990), since both species of hookworm used in this study were adapted to passage through hamsters and were not tested in their natural definitive hosts. However, our results with pyrantel were reassuring since we concluded that A.ceylanicum was marginally, if at all, more sensitive to pyrantel than N.americanus, and this is consistent with the reported comparable efficacy of pyrantel against both human hookworms (Ghadirian \& Sanati, 1972; Rossignol, 1990). The standard treatment for humans is $10 \mathrm{mg} \mathrm{kg}^{-1}$ of pyrantel base for 3 days (Migasena \& Gilles, 1991) which, taking relative body size into consideration, is also close to our values for over $90 \%$ efficacy in hamsters. Furthermore, our $\mathrm{ED}_{50}$ value for N.americanus $(5-25 \mathrm{mg}$ $\mathrm{kg}^{-1}$ was similar to that of $23.3 \mathrm{mg} \mathrm{kg}^{-1}$ given by Rajasekariah et al. (1989).

However, the most interesting conclusion from this study is that N.americanus is extremely resistant to ivermectin, more so than Heligmosomoides polygyrus which is reputed for its insensitivity to this anthelmintic (Wahid et al. 1989). The intriguing question which follows is why 2 organisms, representing 2 genera closely related to each other, should show such marked disparity in sensitivity to ivermectin, despite comparable sensitivities to other commonly employed anthelmintics. It may also be pertinent that hookworms of the genera Bunostomum and Gaigeria (see Yazwinski, 1988; Benz, Roncalli \& Gross, 1989) which are more closely related to Necator than Ancylostoma are sensitive to ivermectin at doses of $<200 \mu \mathrm{g} \mathrm{kg}^{-1}$. One possibility may be that in vivo, subcutaneously injected ivermectin has less access to N.americants than to worms of other hookworm genera and in this context A.duodenale generally penetrate deeper into the gut mucosa than $N$.americanus (see Bonne, 1942; Zimmerman, 1946). Furthermore, A.duodenale is known to cause more profound blood loss than N.americanus in humans (Roche \& Layrisse, 1966) but in our system A.ceylanicum is comparably the more 
pathogenic (Behnke, 1991). However, we feel that this is an unlikely explanation for the relative insensitivity of N.americanus to ivermectin because other parasites such as Ascaris lumbricoides are extremely sensitive to ivermectin in orally treated patients whereas N.americanus is not. Furthermore, Uncinaria stenocephala and A.brazilicnse (see Egerton et al., 1985; Henriques, Martin \& Sievers, 1985; Campbell, 1989 ) which cause only minimal blood loss and are regarded as mucosal surface browsers, are sensitive to subcutaneously administered ivermectin at doses of $<$ $50 \mu \mathrm{g} \mathrm{kg}^{-1}$.

Although it was originally widely believed that the principal target of ivermectin was GABA mediated transmission of signals to longitudinal muscles (Campbell, 1985) the exact mode of action is now disputed. The physiological effect of ivermectin is an increase in permeability of cell membranes to chloride ions (Turner \& Schaeffer, 1989) and it has recently been proposed that a novel $\mathrm{Cl}^{-}$channel may be the receptor (reviewed Geary, Klein, Vanover, Bowman \& Thompson, 1992). In Caenorhabditis elegans ivermectin mediates its effect by binding to a specific high affinity binding site. The differential sensitivity observed in our experiments may thus result from some fundamental difference in the binding sites or chloride channels between worms from the genera Ancylostoma and Necator; but the differential susceptibility of dogs to ivermectin has been clearly demonstrated not to be a result of chloride channel binding (Schaeffer, Rohrer, Cully \& Arena, 1992) and hence there may be other explanations. Since there is evidence that ivermectin passes through the nematode cuticle (Ho, Geary, Barsuhn, Sims \& Thompson, 1992), our observations may suggest fundamental differences in the organization of the cuticle, perhaps at the molecular level. Alternatively differences between the genera in permeability to ivermectin at the gut level following oral ingestion by the parasites or through cuticular pores associated with excretory activity or sensory structures such as cuticular papillae, amphids and phasmids may result in less ivermectin having access to relevant nerve junctions in worms of the genus Necator compared with Ancylostoma. Pharmacokinetic differences between the genera may be responsible for different concentrations of ivermectin reaching target sites. Such differences have been proposed to account for resistance of insects to commercial insecticides (Ahn, Funabi \& Motoyama, 1992). One way to establish whether ivermectin has comparable or differential access to the nervous systems of Ancylostoma and Necator would be to employ fluorescent labelled ivermectin to quantify drug concentrations at nerve junctions following uniform exposure in vitro and/or in vivo
(Martin, Kusel, Robertson, Minta \& Haugland, 1992), an approach which we are currently investigating.

Acknowledgements-We are indebted to the Colt Foundation for its generous support for this project and to the SERC for the provision of a postgraduate research studentship for P. Garside. We thank Dr N. Evans of Pfizer, U.K., for the donation of Strongid $P$ paste and MSD for Ivomec, Dr I.R. Duce for his advice with the manuscript and Mrs J. Brown and Ms J. Street for technical assistance. We are grateful to Profs D. Wakelin and P.N.R. Usherwood for making available to us facilities for our research programme.

\section{REFERENCES}

Ahn Y.J., Finari E. \& Motoyama N. 1992. Mechanisms of resistance to pyrethroids and DDT in a Japanese strain of the housefly. In: Neurotox '91. Molecular Basis of Drug and Pesticide Action (Edited by DucE I. R.), pp. 257-269. Elsevier, London.

Behnke J. M., Wells C. \& Brown J. 1986. An improved technique for experimental infections with skin penetrating nematode larvae (Necator americanus). International Journal for Parasitology 16: 461-464.

BEHNKE J. M. 1990. Laboratory animal models. In: Hookworm Disease. Current Status and New Directions, (Edited by Schad G. A. \& Warren K. S.), pp. 105-128. Taylor \& Francis, London.

Behnke J. M. 1991. Pathology. In: Human Parasitic Diseases, Vol. 4, Hookworm Infections, (Edited by Gilles H. M. \& Ball P. A. J.), pp. 51-91. Elsevier, Amsterdam.

Benz G. W., Roncalli R. A. \& Gross S. J. 1989. Use of ivermectin in cattle, sheep, goats and swine. In: Ivermectin and Abamectin, (Edited by CAMPBELL W. C.), pp. 215-229. Springer, New York.

Bonne C. 1942. Invasion of the wall of the human intestine by ancylostomes American Journal of Medicine 22: 507-509.

Campbell W. C. 1985. Ivermectin: an update. Parasitology Today 1: 10-16.

Camprell W. C. 1989. Use of ivermectin in dogs and cats. In: Ivermectin and Abamectin, (Edited by CAMPBELL W. C.), pp. 245-259. Springer, New York.

Egerton J. R., Eary C. H. \& Suhayda D. 1985. Dosetitration studies of ivermectin against experimental Ancylostoma caninum and Uncinaria stenocephala infections. American Journal of Veterinary Research 46: 1057-1059.

Fukase T., In T., Chinone S., Akihama S. \& Itagaki H. 1991. Anthelmintic efficacy of milbemycin $\mathrm{D}$ against Toxocara cati and Ancylostoma tubaeforme in domestic cats. Journal of Veterinary Medical Science 53: 817-821.

Garsinf P. \& Bf.hnke J. M. 1989. Ancylastoma ceylanicum: observations on host-parasite relationship during primary infection. Parasitology 98: 283-289.

Geary T. G., Klein R. D., Vanover I., Bowman J. W. \& Thompson D. V. 1992. The nervous systems of helminths as targets for drugs. Journal of Parasitology 78: 215-230.

Ghadirian E. \& Sanati A. 1972. Preliminary studies on the treatment of hookworm with pyrantel pamoate in Iran. Journal of Tropical Medicine and Hygiene 75: 199-201. 
Greene B. M., Brown K. R. \& TAylor H. R. 1989. Use of ivermectin in humans. In: Ivermectin and Abamectin (Edited by Campbell W. C.), pp. 311-323. Springer, New York.

Henriques J. E., Martin R. \& Sievers G. 1985. Efticacy of ivermectin against Uncinaria stenocephala in dogs. Archivos de Medicina Veterinaria 17: 99-102.

Ho N. F. H., Geary T. G., Barsuhn C. L., Sims S. M. \& Thompson D. P. 1992. Mechanistic studies in the transcuticular delivery of antiparasitic drugs. 2. Ex vivo in vivo correlation of solute transport by Ascaris suum. Molecular and Biochemical Parasitology 52: 1-14.

Leiby D., El NaGgar H. \& Schad G. A. 1987. Thirty generations of Ancylostoma duodenale in laboratory reared beagles. Journal of Parasitology 73: 844-848.

Martin R. J., Kusel J. R., Robertson S. J., Minta A. \& Haugland T. R. 1992. Distribution of a fluorescent ivermectin probe, bodily ivermectin, in tissues of the nematode parasite Ascaris suum. Parasitology Research 78: 341-348.

Migasena S. \& Gilles H. M. 1991. Treatment of disease. In: Human Parasitic Diseases, Vol. 4, Hookworm Infections (Edited by Gilles H. M. \& BaLl. P. A. J.), pp. 195-203. Elsevier, Amsterdam.

Naquira C., Jimenez G., Guerra J. G., Bernal R., Nalin D. R., Neu D. \& AzIZ M. 1989. Ivermectin for human strongyloidiasis and other intestinal helminths. American Journal of Tropical Medicine and Hygiene 40: 304-309.

Rajasekariah G. R., Deb B. N., Dhage K. R. \& Bose S. 1985. Site of resistance to Necator americanus in hamsters. Acta Tropica 42: 333-340.

Rajasekariah G. R., Deb B. N., Dhage K. R. \& Bose S. 1989. Response of adult Necator americanus to some known anthelminthics in hamsters. Annals of Tropical Medicine and Parasitology 83: 279-285.

Richard-Lenoble D., Kombila M., Rupp E. A., Pappayliou E. S., Gaxotte P., Nguiri C. \& Aziz M. A. 1988. Ivermectin in loiasis and concurrent O.volvulus and M.perstans infections. American Journal of Tropical Medicine and Hygiene 39: 480-483.
RoChe M. \& LAYRisse M. 1966. The nature and causes of hookworm anemia. American Journal of Tropical Medicine and Hygiene 15: 1031-1100.

Rossignol J. F. 1990. Chemotherapy: present status. In: Hookworm Disease. Current Status and New Directions (Edited by Schad G. A. \& Warren K. S.), pp. 281-290. Taylor \& Francis, London.

Schaeffer J. M., Rohrer S. P., Cully D. \& Arena J. 1992. Avermectins: idiosyncratic toxicity in a subpopulation of collie dogs. In: Neurotox '91. Molecular Basis of Drug and Pesticide Action (Edited by DUCE I. R.), pp. 71-76. Elsevier, London.

SEN H. G. 1972. Necator americanus: behaviour in hamsters. Experimental Parasitology 32: 26-32.

Sokal R. R. \& Rohlf F. J. 1969. Biometry. Freeman, San Francisco.

Turner M. J. \& Schaeffer J. M. 1989. Mode of action of ivermectin. In: Ivermectin and Abamectin (Edited by Campbell W. C.), pp. 73-88. Springer, New York.

Wahid F. N., Behnke J. M. \& Conway D. J. 1989. Factors affecting the efficacy of ivermectin against Heligmosomoides polygyrus (Nematospiroides dubius) in mice. Veterinary Parasitology 32: 325-340.

Wang C. I., Huang X. X., Zhang Y. Q., Yen Q. Y.\& Wen Y. 1989. Efficacy of ivermectin in hookworms as examined in Ancylostoma caninum infections. Journal of Parasitology 75: 373-377.

Whitworth J. A. G., Morgan D., Maude G. H., MCNicholas A. M. \& TAYlor D. W. 1991. A field study of the effect of ivermectin on intestinal helminths in man. Transactions of the Royal Society of Tropical Medicine and Hygiene 85: 232-234.

YAZWINSKI T. A. 1988. Use of febantel or ivermectin for treatment of calves with experimentally induced Bunostomum phlebotomum infection. American Journal of Veterinary Research 49: 1407-1408.

Zimmerman H. M. 1946. Fatal hookworm disease in infancy and childhood on Guam. American Journal of Pathology 22: 1081-1090. 